\section{Ventilation During Cardiac Arrest and After Return of Spontaneous Circulation: Like Father, Like Son?}

\section{To the Editor:}

We read with great interest the paper "Mechanical Ventilation Management During Mechanical Chest Compressions" by Orso et al, ${ }^{1}$ in which they identified available knowledge on mechanical ventilation strategies during cardiopulmonary resuscitation (CPR).

We share their conclusion that there is urgent need to find ventilatory strategies and goals for ventilation during CPR. In a study of blood gas analyses during CPR, our working group has reported an association between blood gas exchange metrics and hospital admission. ${ }^{2}$ Whether this finding is an area for future attempts to improve ventilation in resuscitation care or is simply a sign of cardiopulmonary integrity remains uncertain.

Nevertheless, chest compressions and ventilation interact with each other and can affect each other. That is why we applaud the great effort of Orso et $\mathrm{al}^{1}$ to look specifically into ventilation during ongoing chest compressions in contrast to the much broader topic of ventilation during cardiac arrest, including post-resuscitation care.

Notably, Orso and colleagues ${ }^{1}$ specifi- $^{-}$ cally excluded studies of mechanical ventilation after the return of spontaneous circulation (ROSC). Therefore, we would like to point out that, to our knowledge, the cited paper by Moskowitz et $\mathrm{al}^{3}$ only reports tidal volumes administered immediately after ROSC. A similar problem appears to exist with the cited paper by Ebner et al, ${ }^{4}$ which was a substudy of the Target Temperature Management trial that included subjects after out-of-hospital cardiac arrest. More specifically, the authors stated that median time from ROSC to inclusion was 133 (IQR 83-188) $\mathrm{min}^{4}$

In addition, $\mathrm{Oh}$ et $\mathrm{al}^{5}$ gathered data from arterial blood gas analyses within $10 \mathrm{~min}$ after ROSC. While this is not precisely intra-arrest data, ventilation during CPR might be reflected in these measurements. However, we previously found the partial pressure of oxygen to increase rapidly after ROSC. $^{2}$

While the mentioned sources should have been excluded by the defined exclusion criteria, as they primarily analyzed ventilation data after ROSC, the

fact that they have been included further illustrates how scarce our available knowledge regarding ventilation during cardiac arrest is.

It appears to be crucial for further research to point out that the distinction between intra-arrest ventilation and postarrest ventilation has to be maintained as they are fundamentally different interventions in different patient populations with different pathophysiological needs.

\section{Johannes Wittig \\ Medical University of Graz Styria, Austria}

Simon Orlob Gerhard Prause

Division of General Anaesthesiology Emergency and Intensive Care Medicine Medical University of Graz Styria, Austria

Correspondence: Johannes Wittig, Medical University of Graz, Auenbruggerplatz 2, 8036 Graz, Styria, Austria. E-mail: johannes.wittig@ stud.medunigraz.at

The authors have disclosed no conflicts of interest.

DOI: $10.4187 /$ respcare. 08791

\section{REFERENCES}

1. Orso D, Vetrugno L, Federici N, Borselli M, Spadaro S, Cammarota G, Bove T. Mechanical ventilation management during mechanical chest compressions. Respir Care 2021;66(2):334-346.

2. Spindelboeck W, Gemes G, Strasser C, Toescher K, Kores B, Metnitz P, et al. Arterial blood gases during and their dynamic changes after cardiopulmonary resuscitation: a prospective clinical study. Resuscitation 2016;106:24-29.

3. Moskowitz A, Grossestreuer AV, Berg KM, Patel PV, Ganley S, Casasola Medrano M, et al. The association between tidal volume and neurological outcome following in-hospital cardiac arrest. Resuscitation 2018;124: 106-111.

4. Ebner F, Ullén S, Åneman A, Cronberg T, Mattsson N, Friberg H, et al. Associations between partial pressure of oxygen and neurological outcome in out-of-hospital cardiac arrest patients: an explorative analysis of a randomized trial. Crit Care 2019;23(1):30.

5. Oh YT, Kim YH, Sohn YD, Park SM, Shin DH, Hwang SY, et al. Early hyperoxemia may not increase mortality after cardiac arrest: a pilot study. Clin Exp Emerg Med 2014;1(1):28-34.
Ventilation During Cardiac Arrest and After Return of Spontaneous Circulation: More than a Family Affair ... the Truth Will Be in the Details

Reply:

We thank Wittig and his colleagues for their response to our review. ${ }^{1}$ Indeed, the aim of the work was exactly that: to open up a debate on the topic with the hopeful end result of promoting further scientific inquiry.

At present, evidence regarding the best ventilation modalities and parameters to use for achieving return of spontaneous circulation (ROSC) and adequate neurological performance after ROSC and during cardiopulmonary resuscitation (CPR) — and, even more so, during the use of automatic devices for the delivery of chest compressions-is, to put it mildly, scarce. In our review, we pulled together the little evidence available on this issue, attempting to summarize the state of affairs and, most importantly, place it under the spotlight. Therefore, we agree with Wittig et al that the issues highlighted are still in need of further clarification. We also agree that the issues regarding mechanical ventilation during CPR and after ROSC are different. It was for this reason exactly that we excluded all studies dealing with determining the best ventilatory parameters in subjects who had achieved ROSC but, for whatever reason, still needed to be mechanically ventilated.

Regarding the study by Moskowitz et al, ${ }^{2}$ who tried to establish the relationship between tidal volume and neurological recovery at $6 \mathrm{~h}$ and $48 \mathrm{~h}$ after ROSC, we closely analyzed the data presented in their study and considered it carefully. Although we cited that study for the sake of completeness, we did not consider the evidence it reported to be strong enough to draw any tentative conclusions from it. Indeed, we stated that further evidence is needed before any conclusions can be made about the most effective tidal volume during CPR.

Regarding the studies by Ebner et $\mathrm{al}^{3}$ and Oh et al, ${ }^{4}$ we agree that the $\mathrm{P}_{\mathrm{aO}_{2}}$ in the blood can increase dramatically within just a few minutes after cardiac arrest. We specifically cited these studies to highlight that such controversies exist in the literature regarding the correct amount of oxygen to administer during CPR. In fact, Patel et $\mathrm{al}^{5}$ published a meta-analysis on exactly this topic; although it covered just 


\section{CORRESPONDENCE}

2 trials, it provides the strongest evidence to date on this topic. Our statement regarding hyperoxia being deleterious in the period after ROSC, but potentially having a beneficial effect on the achievement of ROSC during CPR, is based on the evidence provided by Patel and colleagues.

Ultimately, although we tried to summarize the scant evidence available to date, we concur with Wittig et al that new studies on this matter are imperative. We are delighted that our review has already set a wheel in motion and provoked some (family) debate within the medical community, and we hope that this will lead to the instigation of new trials.

Daniele Orso Department of Medicine University of Udine Udine, Italy

\section{Luigi Vetrugno}

Tiziana Bove

Department of Anesthesia and Intensive

Care Clinic

ASUFC University Hospital Santa Maria della Misericordia

Udine, Italy

Correspondence: Luigi Vetrugno MD, Department of Medicine, University of Udine, Udine, Italy. E-mail: luigi.vetrugno@asufc.sanita.fvg.it.

The authors have disclosed no conflicts of interest.

DOI: $10.4187 /$ respcare. 08814

\section{REFERENCES}

1. Orso D, Vetrugno L, Federici N, Borselli M, Spadaro S, Cammarota G, Bove T. Mechanical ventilation management during mechanical chest compressions. Respir Care 2021;66(2):334-346.
2. Moskowitz A, Grossestreuer AV, Berg KM, Patel PV, Ganley S, Casasola Medrano M, et al. The association between tidal volume and neurological outcome following in hospital cardiac arrest. Resuscitation 2018; 124:106-111.

3. Ebner F, Ullén S, Åneman A, Cronberg T, Mattsson N, Friberg H, et al. Associations between partial pressure of oxygen and neurological outcome in out-of-hospital cardiac arrest patients: an explorative analysis of a randomized trial. Crit Care 2019; 23(1):30.

4. Oh YT, Kim YH, Sohn YD, Park SM, Shin DH, Hwang SY, et al. Early hyperoxemia may not increase mortality after cardiac arrest: a pilot study. Clin Exp Emerg Med 2014;1(1):28-34.

5. Patel JK, Kataya A, Parikh PB. Association between intra- and post-arrest hyperoxia on mortality in adults with cardiac arrest: A systematic review and meta-analysis. Resuscitation 2018;127:83-88. 